\title{
Theory into Practice: Designing Moodle Training for Change Management
}

\author{
Margot A. McNeill ${ }^{1}$, Lucy S. Arthur ${ }^{1}$, Yvonne A. Breyer ${ }^{2}$, Elaine Huber ${ }^{1} \&$ Amanda J. Parker ${ }^{1}$ \\ ${ }^{1}$ Learning and Teaching Centre, Macquarie University, Sydney, Australia \\ ${ }^{2}$ Faculty of Arts, Macquarie University, Sydney, Australia \\ Correspondence: Margot A. McNeill, Learning and Teaching Centre, Macquarie University, NSW 2109, \\ Australia. Tel: 61-2-9850-9722. E-mail: margot.mcneill@mq.edu.au
}

\author{
Received: September 3, 2012 Accepted: September 24, 2012 Online Published: October 31, 2012 \\ doi:10.5539/ass.v8n14p58 \\ URL: http://dx.doi.org/10.5539/ass.v8n14p58
}

\begin{abstract}
Encouraging academics to use educational technologies to enhance learning and teaching requires building their sense of competence, relatedness and autonomy. This paper describes how self-determination theory was used as the basis of a professional learning program to support a university-wide rollout of a new Learning Management System (LMS). Rather than merely moving from one LMS to another, the move was seen as an opportunity to transform teaching within the online environment and build capability of academic teaching staff to use the new tools sustainably and efficiently in a context of growing numbers of increasingly diverse students. Engaging teaching staff in the professional learning program to foster a sense of autonomy was seen as essential to achieving these aims. The processes used in developing the professional learning program are described, along with indicators of success that are emerging from the initiative.
\end{abstract}

Keywords: change management, professional learning, Moodle, learning management systems, training

\section{Introduction}

The use of Learning Management Systems is widespread in the higher education sector. Some universities see the use of a Learning Management System (LMS) as a move to provide a competitive advantage (Holt and Seagrave 2003), by increasing flexibility. They offer students access to learning "at any time and in any place" (Slevin, 2008, p. 115) and research from Macquarie University (Gosper, Malfroy et al. 2011; McNeill, Diao et al. 2011) and elsewhere indicates that both students and staff value the efficiencies to be gained by using an LMS (Lonn and Teasley 2009).

In 2010, Macquarie University decided to move from the LMS Blackboard to what it considered to be a 'cost-effective' and 'flexible solution' of an Open Source LMS, Moodle (Grob, Bensberg et al. 2004). This LMS option is governed by an open source license which, unlike commercial software, permits anyone to freely use, adapt, restructure and even sell the software under the stipulation that the open source license remains uncompromised (Dougiamas and Taylor 2003). This flexibility, along with the social constructivist philosophy behind the design of Moodle contributes to its rapid rate of adoption in the higher education sector. According to Moodle.org, the majority of Australian universities use Moodle for at least some of their current online or blended delivery (http://Moodle.org/sites/). While the LMS tools may be available for use in social constructivist curriculum models (Papasergiou 2005), taking advantage of these features is only one component of a possible shift to different pedagogical approaches. The currently available literature offers a wealth of information about the contribution of Learning Management Systems to education but there are still some areas where little is known about their impact on learning and teaching. As an example, research undertaken by Weaver et al., (2005) indicates that quality control is a major issue for universities. Student feedback in their study reflected the use of the technology by teaching staff in that students who experienced a well-designed unit, with rich resources, timely feedback and good interaction with staff were more likely to report a positive experience with the LMS. Staff participating in the study were more focused on the technical and administrative aspects of using the LMS rather than teaching issues. These findings reinforce the opportunity for the move to a new system to be viewed as a change management, rather than a migration, activity in order to equip academics to use the LMS tools to enhance student learning. 
Transformation of the online learning environment, rather than simply migrating from the old system to the new, was identified as a key priority for the move to Moodle at Macquarie University. Another key focus was the need to build academics' capability to use the tools themselves, rather than relying on centralised unit development services. In order to progress these aims, a Change Management Stream was introduced in the project to work in parallel with the Technical Stream. Efforts to lead change, as warned by Kotter (2007) have frequently been unsuccessful, and he cites areas such as communicating the vision clearly and often, and embedding changes in the corporate culture as crucial. In order to foster these dual aims of transformation and capability building, a high level of academic engagement was seen as essential, a challenge within itself given the high degree of 'change fatigue' within the sector as a whole. Therefore, as part of the change management initiatives, the professional learning program was designed using self-determination theory as a framework, as described in the next section.

\subsection{Theoretical Framework}

Self-determination theory advocates that different settings can support humans to reach their potential by encouraging them to be competent, related and autonomous (Deci and Ryan 2008). Reasons behind the individual's motivation and the extent of their participation in activities can be organized along a continuum of behaviour (Kipp \& Amarose, 2008), ranging from intrinsic motivation at one end to amotivation at the other end. Intrinsic motivation in this case refers to the personal fulfilment and satisfaction associated with involvement, likely when the activity leads to the fulfilment of three basic psychological needs: competence, autonomy and relatedness. Competence involves a feeling of being effective at a certain task; autonomy is perceived as having both a choice in and control over one's own behaviour and relatedness is a sense of belonging toward others.

Amotivation is lacking intention or reasons for participation and includes a feeling of powerlessness to produce any desired result with their behaviour (Walker, Foster, Daubert \& Nathan, 2005). In the middle of the continuum, between intrinsic motivation and amotivation, is extrinsic motivation. Extrinsic motivation is characterised by participation in an activity to achieve some other desired end (Kipp \& Amarose, 2008; Wilson, Mack \& Grattan, 2008). Individuals' motivation can be powerful predictors of outcomes such as effective performance, creative problem solving, persistence and health and wellbeing, important characteristics if academics are to continue to learn about and implement new technologies sustainably.

According to the mini-theories underpinning self-determination theory (Deci \& Ryan, 2000), settings that encourage intrinsic motivation build:

\section{Competence}

Causality Orientations Theory (COT) suggests that if individuals experience anxiety concerning their competence, they are more likely to gravitate toward an amotivated orientation on the continuum. Cognitive Evaluation Theory (CET) suggests that factors such as rewards and positive feedback have positive effects on intrinsic motivation if individuals perceive themselves to be competent. To build this sense of competence, the range of training offerings needs to be broad enough to build on individuals' existing knowledge.

\section{Relatedness}

Relatedness encompasses both the level of relatedness individuals perceive between their own values and belief system and the context, and also the strength of their networks with others. Organismic Integration Theory (OIT) suggests that contexts which relate to individual's values, goals or belief systems are more likely to be internalised and lead to intrinsic motivation. Goal Contents Theory (GCT) further differentiates between intrinsic and extrinsic goals and their impact on motivation and also wellness, concluding that intrinsic goals such as close relationships are associated with higher levels of wellness than extrinsic goals such as financial reward.

\section{Autonomy}

In explaining their theory, Deci and Ryan advocate 'autonomy' as 'perhaps the central need in self-determination', resulting from the satisfaction of individuals' need for relatedness and competence rather than as a separate need (2008, p. 392)

Although the studies informing self-determination theory were mostly conducted in experimental environments with undergraduate psychology students, the key components of competence, relatedness and autonomy were seen as requirements in order for academics to continue to use the dynamic system to enhance teaching and learning, hence it was applied to the change management planning.

\section{The Change Management Program}

In order to further the project aims of transformation and capability-building, the change management program 
had three components; implementation, communication and training and resources. Each of these areas was led by the central project team:

1) The Implementation Coordinator led the development of pilots to trial the new system and develop initial templates;

2) The Communications and Customer Support Officer collated project-wide information and provided generic newsletters, FAQs and announcements;

3) The Training and Development Officer led the development of learning materials for face-to-face workshops, online training and quick guides for individual access.

In addition to this central staffing, each faculty was assigned:

1) A Liaison Officer to coordinate the development of faculty implementation plans, templates and communication strategies;

2) A full-time continuing Training and Support Officer;

3) An Educational Developer and Online Educational Designer to work with staff on curriculum redesign;

4) Access to a pool of 8 web content developers to help with tasks such as moving content around within the new Moodle sites and adding faculty-wide links that were not yet included in faculty templates.

Three of these supporting positions are ongoing (Training and Support Officers, Educational Developers and Online Educational Designers) and will continue after the implementation; however the remainder are project-funded to provide additional help to academics as they move to a more autonomous position in which they have full control over the design of their units. This level of support was seen as essential given the University's previous models where academics frequently relied on instructional designers to develop their units and were subsequently reliant on programming help by web developers for making even the most basic of changes such as fixing typos or adding links to dynamic content such as newspaper articles. Building the academics' capability and encouraging greater autonomy over their unit content was identified as a priority in the change management process, especially given the choice of Moodle as an easy-to-use system designed for university-wide implementation.

\subsection{Competence and the Bell Curve of Support Requirements}

In order to design a professional development program to suit the needs of individuals, an understanding of the expertise of the academics who would use the system was required.

From discussions with the Educational Developers and technical support officers involved in previous projects, a pattern of support requirements seems to be emerging of a bell curve (Rogers 1995).

Early adopters -technology savvy and keen to explore new opportunities.

Early middle - individuals in this category are also keen, but are likely to be less technically able and will rely more on our support.

Late middle - less technically savvy and less confident in their curriculum design capacity. These individuals were identified as likely to need most technical support.

Laggards - these are not likely to need much of our curriculum design help. These people would benefit from a pool of casual staff helping them move their content across to the new system.

In order to scaffold academics toward competence, the training series was also designed to support proactive and retroactive facilitation (Keppel and Underwood 1962), where previous learning provides a foundation for new learning and helps explain past experiences. To build their perception of competence and enable the academics to choose options to best suit their needs, training was designed to be available face-to-face and online.

The options were:

Tours - a demonstration to familiarise staff with the functionality of the new system. These were available centrally for any staff to attend so they could see what is available and liaise with those from other faculties. There were also faculty and departmental tours, sometimes conducted as part of regular meetings.

Moodle Basics - hands-on introduction workshops for unit convenors, providing an introduction to building and editing an online unit. Introductory workshops for tutors also covered the skills specific for tutoring staff teaching with Moodle.

Moving to Moodle workshops - to build staff confidence, hands-on workshops were planned so convenors 
could come and work on their own units with help from members of the support team. These sessions were available for small groups, campus wide, or in faculty or department groups, with a ratio of 12 attendees to 3 trainers from the Moodle teams.

Specific Moodle Tools workshops - to build competence and encourage academics to be innovative in using specific tools, sessions were designed to demonstrate Moodle tools. Academics could use these sessions to work on implementing new tools into their units. Again these sessions were sometimes delivered for department or faculty groups, to encourage networking and collaboration between academics. Initially these sessions were on:

Quizzes

Forums

Wikis

Groups

Databases

Assessment tools

Gradebook

Turn-it-in

Self-help resources in varying formats (print, web and media) were designed to cover these topics and made available for those who preferred to explore the new system unaided.

\subsection{Centralised Processes to Provide Systematic Support and Training}

The Faculty team's approach was to ensure staff were able to access efficiently the support and information they need, to encourage confidence in the system so that they can then become competent users.

This included:

A 'Request For Assistance' Process by which staff could access training, design and development assistance (offered to all unit conveners individually);

A Training and Support Officer based permanently in the Faculty four days per week, and available every day for individual consultations and tailored training sessions;

The centralised help ticket system for technical issues;

A communication flow channelled through the faculty Liaison Officer, ensuring enquiries were responded to promptly and authoritatively, and that staff all received the same information;

Efficient client information management via online databases of all training attendances and unit activity.

Where Departments offer their own support, the faculty teams worked together with local support in order to be efficient and sustainable, and in order to ensure that the implementation could be monitored accurately in the Department.

\subsection{Changing toward a Culture of Relatedness}

The faculty liaison teams worked to encourage relatedness between academics by showcasing example units that demonstrated features relevant for specific contexts. Early adopters were encouraged to share their experiences, positive and negative, to encourage peer learning. These faculty teams were well positioned to maximise opportunities for transformation within departments, for instance by facilitating program-wide conversations around curriculum design and online learning. This is a substantial and a welcome change from the University's long-standing culture of individualised approaches to unit design, which is now at odds with the push toward graduate capabilities requiring a longer development time than one unit. In order to hone their skills in teamwork, communication or problem solving, students need scaffolding across their whole program, with content and processes increasing in complexity.

\subsection{Building Autonomy}

Once academics have been to training, they were encouraged to access the series of online resources to remind themselves of what they have learned and explore new functions. Currently there are numerous online resources including:

82 Quick Guides;

24 Fact and Information Sheets;

34 Example units; 
8 Student information pages with more in development.

The progress made toward Quality Assurance (QA) in each faculty has been designed toward building academic autonomy. Scalable and sustainable use of Moodle, to meet the needs of growing and increasingly diverse cohorts of students requires that unit conveners are responsible for the learning technologies used in their units, in accordance with department and faculty arrangements. To support the convenors in using technologies effectively, QA processes are being developed with faculty teams to support staff in using the new LMS platform to enhance student learning and comply with University policy. Quality Enhancement (QE) processes will support reflection on what content and learning designs they need to keep, what worked and what didn't and what they would like to add. The quality enhancement processes built into the planning include peer review programs, to encourage professional conversations amongst academics and build autonomy by enabling them to develop self-assessment skills as they review the curriculum design or other aspect of their peers' teaching. Another contributor to the academics' sense of autonomy is the development of clear roles and responsibilities for the new LMS. To maintain the integrity of the online spaces as part of academics' responsibility, limitations on what instructional designers can do in the online spaces have been agreed and embedded into policy: e.g., convenors are responsible for content and those with support access can go in to the online space to provide assistance and guidance but should not enter or change content without the convenors' express permission.

\section{Discussion}

The aims of the Change Management project were:

Transformation - in order to deliver sustainable and scalable online units as student numbers grow, academics need to be able to respond in a timely manner by adapting their curriculum and using new tools to enhance student learning;

Capability building - equipping academics with the skills to develop and deliver their own units in the new, user-friendly online platform.

The new system (Moodle) was specifically chosen for its easy-to-use and flexible functionality. Traditionally many academics have been excluded from accessing their own online content, and the change to a new LMS provided a great opportunity for the University to move away from these practices. Leading change is a long term process (Kotter 2007) and the evaluation of the project to introduce the new LMS involves the collection of large amounts of qualitative and quantitative data from teaching staff, students and the project team. Although the project evaluation as a whole is still underway, there is evidence of success when considering the change management program through the self-determination theory framework. Some of these successes are described here:

\subsection{Competence}

Given the range of skill and engagement levels of the teaching academics, a key criterion of the training suite was scaffolding, from the initial tours to familiarise staff with the new environment, to moving to Moodle workshops and those exploring specific tools such as the Gradebook and assessment functions. Initial feedback indicates that this range of offerings and incremental introduction to the new environment built academics' confidence in their ability to manage the new LMS. It is particularly telling that $84 \%$ more online units were delivered for Session 1, 2012, using the new LMS (up from 760 Semester 1, 2011 to 1402 in Session 1, 2012). Given this marked increase in online offerings, along with the additional complexity of changed processes for integrating the new system with legacy systems (and a new digital lecture recording system) the IT Support Team's reported drop in Help tickets of $32 \%$. Surveys and focus groups are currently underway to collect qualitative and quantitative data for evaluation reporting. A total of 970 units were targeted for the minimum standards introduced for Moodle for Session 1, with all but 28 meeting the faculty minimum standards.

\subsection{Relatedness}

Relatedness enables academics to see that the new system can provide benefits for themselves and their students and that they are part of a community of learners in a dynamic environment. The choice of the new system, Moodle, was informed by research conducted into the needs of the students and staff during the consultation process. After Moodle was selected, the priorities for the training and resources suite were designed around the feedback gathered from staff and students in the lead up to the implementation. Anecdotal evidence from the academics so far is encouraging in that this degree of authenticity and evidence-based decision making instilled confidence that functions were built around what we know from research into staff and student uses, e.g. online assignments.

Relatedness according to self-determination theory also includes the extent to which the context operates within 
a community. In order to build a sense of community amongst the academics, strategies were planned to involve the faculties and departments in decision-making. Faculty teams were encouraged to link in with existing procedures for communication for example departmental meeting schedules. Early adopters were fostered into a group of champions who could spread the good word about their discoveries of the new system. A 'Breakfast of Champions' was held each semester to welcome these early adopters, providing networking opportunities for them and encouraging their advocacy.

Showcasing was another strategy for encouraging this sense of relatedness - a total of 34 example units was developed during the trial period, one from each department so that academics could see the new system in use in a unit in some way related to theirs. These example units are available in an online site with the various categories around their department and the types of tools and curriculum designs used. It was essential that these example units are designed to encourage academics to try out ideas in their own unit rather than being seen to be too complex and beyond their competence level. If the exemplar units are too far removed from convenors' experience, COT and CET theories suggest that this will be demotivating. A live showcase session was presented during the University's Learning and Teaching Week in 2011 and since then faculties have planned and delivered additional opportunities at lunchtimes or in scheduled meetings.

All of these initiatives contributed to relatedness between the central Learning and Teaching unit and the faculties and departments, which was a key focus of activities. The faculty teams and especially the Training and Support Officers worked to build relationships based on trust with individuals and groups, which will be essential as new technologies continue to be introduced.

\subsection{Autonomy}

The professional learning program was designed to build academics' sense of autonomy as they could progress from an introductory tour, to sessions providing basics, opportunities for hands-on moving and exploration of specific tools. These face-to-face sessions could then be supplemented by a range of online training resources. Although the evaluation has not yet begun to determine the project's success in achieving these aims, there are promising indicators so far including a total of 1973 attendances recorded at tours, training sessions and workshops. Following on from these sessions, 428 attendances were recorded at the Drop-In Clinic, run in the week prior to and two weeks immediately after the launch of the new system. These sessions, as part of the wider training and support program, have helped in building up goodwill and engagement and plans are being considered to extend the clinics on an ongoing basis.

Reflections from members of the training team as part of the overall evaluation capture the evidence of the development of autonomy to date, such as the types of requests changing from using the tools to adding new tools or strategies. For example, many staff members followed up attendance at workshops with a call to the Drop-in Clinic to ask for a refresher or 'someone to just check over their unit.' The high level of activity on the Moodle web pages which contained quick guides and supporting resources is another indication of the academics' increasing level of autonomy. While the number of help desk tickets was reduced by $32 \%$, there were 5,378 views of the Moodle Quick Guides page, 1440 views on the FAQs and 4,630 views on the training page.

Self-service, to meet their own learning needs is one of the characteristics of an autonomous learner, and there is evidence of increased use of the online supporting resources. The LMS portal including Moodle had a total of 83,078 views altogether, in the period 1 October 2011 to 16 March 2012, with a sudden spike in usage just at the end of February. The peak day was Monday 27 February, 2012, first day of semester, with 2415 hits. From there it declined every day that week to about 1000 hits on the Friday. In the last month only $23 \%$ of web site users were returning visitors. Almost $77 \%$ of hits were from users who had never accessed the site before.

\section{Conclusion}

In conclusion, using the new LMS as a catalyst for change management required a multi-faceted approach. Building academics' capability to take advantage of the new system to enhance learning required a range of information and training sessions to cater for different levels of experience and confidence. Communication employed different modes, from university-wide newsletters to working with faculty teams and early adopters to 'spread the good word'. Scaffolding skill levels and engaging academics in using the tools to drive pedagogical change required gathering their feedback during development of templates and keeping them in the loop as changes and enhancements were made. Showcasing good practice in example units and encouraging professional conversations through peer observation were important in the shift from quality assurance to quality enhancement.

Although this is only the beginning of the journey, transformation of units has taken place in many cases, and the faculty teams have worked with many convenors on using different tools in their units. As an example, increased 
uptake of online marking with Turnitin/Grademark with its 'all-in-one/simple design' approach, has encouraged many conversations about academic honesty in units, using rubrics for assessment, more consistent marking across large tutor groups as well as evaluations of statistics output from this system. Building sustainability into the change management plans has been a constant challenge, for example balancing the provision of enough support to help academics transform their units, without undermining the overall capability-building aim; balance between the popularity of the one-to-one drop in clinics and skill building focus of the structured training programs. The focus for faculty teams is shifting towards embedding the use of the LMS into academic practice to maintain the momentum into next year and beyond, and the development of Style Guides and good practice checklists to enhance the self-determination of the academics, essential in the dynamic environment of online learning.

\section{References}

Deci, E. L., \& Ryan, R. M. (2008). Self-determination theory: A macrotheory of human motivation, development and health. Canadian Psychology, 49, 182-185. http://dx.doi.org/10.1037/a0012801

Dougiamas, M., \& Taylor, P. (2003). Moodle: Using Learning Communities to Create an Open Source Course Management System. World Conference on Educational Multimedia, Hypermedia and Telecommunications (EDMEDIA): Proceedings of World Conference on Educational Multimedia, Hypermedia and Telecommunications Honolulu, Hawaii, USA, ED-MEDIA.

Gosper et al. (2011). Students' Engagement with Technologies: implications for University Practice. Changing Demands, Changing Directions. Proceedings ASCILITE, Hobart. http://dx.doi.org/10.2498/cit.2004.02.08

Grob et al. (2004). Developing, Deploying, Using and Evaluating an Open Source Learning Management System. Journal of Computing and Information Technology, 12(2), 127-134.

Holt, A., \& Seagrave, S. (2003). Creating and Sustaining Quality E-Learning Environments of Enduring Value for Teachers and Learners. Interact, Integrate, Impact: Proceedings of the 20th Annual Conference of the Australasian Society for Computers in Learning in Tertiary Education, Adelaide, 7-10 December 2003.

Keppel, G., \& Underwood, B. (1962). Proactive inhibition in short-term retention of single items. Journal of Verbal Learning and Verbal Behavior, 1(3), 153-161. http://dx.doi.org/10.1016/S0022-5371(62)80023-1

Kotter, J. (2007, January). Leading change: Why transformation efforts fail. Harvard Business Review, 1, 96-103.

Lonn, S., \& Teasley, S. (2009). Saving time or innovating practice: Investigating perceptions and uses of Learning Management Systems. Computers \& Education, 53, 686-694. http://dx.doi.org/10.1016/j.compedu.2009.04.008

McNeill et al. (2011). Student uses of technology in learning: two lenses. Interactive Technology and Smart Education, 8(1), 5-17. http://dx.doi.org/10.1108/17415651111125478

Papasergiou, M. (2005). Management systems as tools for the creation of online learning environments: Evaluation from a social constructivist perspective and implications for their design. International Journal on E-Learning, 5(4), 593-622.

Rogers, E. M. (1995). Diffusion of Innovations. New York, Free press. 